Review Article

\title{
Dopamine in the Pathophysiology of Preeclampsia and Gestational Hypertension: Monoamine Oxidase (MAO) and Catechol-O-methyl Transferase (COMT) as Possible Mechanisms
}

\author{
Wendy N. Phoswa \\ Department of Life and Consumer Sciences, University of South Africa (UNISA), Science Campus, Private Bag X6, Florida, \\ Roodepoort 1710, South Africa \\ Correspondence should be addressed to Wendy N. Phoswa; phoswawendy@gmail.com
}

Received 7 June 2019; Revised 29 October 2019; Accepted 19 November 2019; Published 28 November 2019

Academic Editor: Ryuichi Morishita

Copyright ( 2019 Wendy N. Phoswa. This is an open access article distributed under the Creative Commons Attribution License, which permits unrestricted use, distribution, and reproduction in any medium, provided the original work is properly cited.

\begin{abstract}
Purpose of the Review. Hypertension in pregnancy is the global health burden. Amongst the hypertensive disorders of pregnancy, preeclampsia and gestational hypertension are the world's leading disorders that lead to both maternal and fetal morbidity and mortality. Recent Findings. Dopamine inactive metabolites, namely, monoamine oxidase (MAO) and catechol-O-methyl transferase (COMT), have been reported to be associated with hypertensive disorders of pregnancy such preeclampsia and gestational hypertension. Summary. This review discusses the involvement of MAO and COMT in the pathophysiology of both conditions in order to have a better understanding on the pathogenesis of both conditions, suggesting promising therapeutic interventions and subsequently reducing maternal and fetal morbidity and mortality.
\end{abstract}

\section{Introduction}

Apart from preeclampsia (PE) which accounts $70 \%$ of all hypertensive cases of pregnancy, gestational hypertension $(\mathrm{GH})$ is also one of the life-threatening illnesses associated with hypertensive disorders of pregnancy (HDP). Gestational hypertension, also known as pregnancy-induced hypertension (PIH) without proteinuria, makes up to $10 \%$ of HDP with significant variations in certain parts of the world depending on diagnostic criteria [1].

Preeclampsia is defined as elevated blood pressure (SBP $\geq 140 \mathrm{mmHg}$ or DBP $\geq 90 \mathrm{mmHg}$ ) after 20 weeks of gestation in a previously normotensive woman [2] without proteinuria. Both PE and GH have similar risk factors (e.g., high BMI, type 1 diabetes, and gestational diabetes) which contribute to the pathogenesis of the disease.

There is still ongoing debate as to whether PE which is associated with elevated protein excretion is a different condition to nonproteinuric hypertension (gestational hyperten- sion) or whether it is indeed a different part of a spectrum of the same disease $[2,3]$. Although the pathophysiology of GH and PE has been reported to emanate from increased oxidative stress which results from reduced placental perfusion followed by exaggerated maternal inflammatory response and endothelial dysfunction [4-6], the exact pathophysiology that leads to the clinical features of both conditions still remains undefined.

Over the last decade, substantial progress has been made in understanding the pathophysiology of both conditions. Recent reports point towards the dopamine bioavailability. It has been reported that altered levels of dopamine production may lead to a number of pathologies including oxidative stress, edema, and either genetic or essential hypertension [7].

\section{Dopamine-Induced Oxidative Stress}

Dopamine has been reported as one of the major sources of oxidative stress. This oxidation occurs through the activity 
of an enzyme known as prostaglandin $\mathrm{H}$ synthase [8] or with mitochondrial proteins [9]. Additionally, dopamine induces oxidative stress via monoamine oxidase (MAO) activity $[10,11]$.

Dopamine-induced oxidative stress has been implicated to be involved in aging and neurodegeneration disorders such as schizophrenia and Parkinson disease [12-15]. A study conducted by Grima et al. showed that dopamine decreases glutathione by $40 \%$ [12]. Glutathione is an antioxidant that plays a crucial role in protecting the cells from damage by reactive oxygen species generated by dopamine metabolism [12].

\section{Dopamine Metabolism}

Dopamine is broken down into inactive metabolites by a set of enzymes-monoamine oxidase (MAO), catechol-Omethyl transferase (COMT), and aldehyde dehydrogenase (ALDH). Both MAO and COMT have been found to play a role in normal placental development, and the absence or excessive production of these enzymes has been associated with hypertensive disorders of pregnancy [16-18].

Monoamine oxidase (MAO) is an enzyme involved in the oxidative deamination of amine neurotransmitters, including noradrenaline, serotonin, and dopamine, and exists as two isoenzymes, MAO-A and MAO-B. These enzymes differ in substrate specificity $[19,20]$ and tissue expression. MAO-A is predominant in the placenta compared to MAO-B which is present at low levels [21]. MAO-B enzyme is also present in platelet and lymphocytes [22].

\section{The Role of Monoamine Oxidase (MAO) in the Pathophysiology of Hypertensive Disorders of Pregnancy}

In the placenta, MAO has been reported to play an essential role in protecting the fetus since MAO inhibition has been found to lead to fetal growth restriction and pregnancy loss [23-25]. Interestingly, it has also been suggested that MAO is involved in the regulation of fetomaternal blood flow [26]. Although studies have indicated the importance of MAO in normal pregnancy, there is currently no data reported in relation to the role of MAO in hypertensive disorders of pregnancy. Therefore, more studies are needed in order to understand the role of this enzyme in the pathophysiology of hypertensive disorders of pregnancy. Current studies have however reported on the role of this enzyme to be associated with endothelial dysfunction [27, 28].

4.1. Monoamine Oxidase-Induced Endothelial Dysfunction. Endothelial dysfunction is one of the factors that lead to the pathogenesis of both PE and GH [29, 30]. MAO has been reported as a mediator for endothelial dysfunction [31]. Several studies have reported on the endothelial dysfunction induced by MAO [32, 33]. A study conducted by Sturza et al. reported that MAO-A and MAO-B contribute to the development of endothelial dysfunction through the activation of reactive oxygen species in the mouse aorta [27]. Similarly, Sun et al. reported that increased MAO-A expres- sion in endothelial cells and cardiomyocytes contributes to vascular dysfunction and left heart failure [28].

Additionally, Sturza et al. showed that MAO induced endothelial dysfunction by increasing reactive oxygen species (ROS) in diabetic rats [34]. Similar findings were previously observed by Kluge et al. [33]. Interestingly, inhibition of MAO has been shown to successfully improve endothelial function and various studies have supported this finding. Sturza et al. showed that MAO inhibition can potentiate restoring endothelium-dependent relaxation in an experimental model of hypertension in a rat [34]. Furthermore, they also demonstrated that MAO-A inhibition improves endothelial dysfunction in Zucker diabetic fatty (ZDF) rat, a genetic model of type 2 diabetes [32]. Similarly, Lighezan et al. reported that MAO inhibitors restore endothelial function in conditions associated with increased oxidative stress [35].

4.2. Monoamine Oxidase-Induced Oxidative Stress. Monoamine oxidase (MAO) is also known as the primary source of oxidative stress [36]. MAO has been reported to play a role in the pathophysiology of hypertensive disorders of pregnancy [37]. This occurs as a result of increased oxidative stress induced by MAO. However, inhibition of MAO activity has been reported to reduce the vascular formation of reactive oxygen species, $\left(\mathrm{H}_{2} \mathrm{O}_{2}\right)$, and partially leads to improved endothelium-dependent relaxation in vessels preexposed to angiotensin II and lipopolysaccharide [27].

Oxidative stress is the major factor involved in the pathophysiology of both PE and GH. Several studies have reported that there is increased oxidative stress in both conditions [38-42].

MAO-induced oxidative stress occurs when a FAD cofactor catalyses the oxidative deamination of several monoamines (e.g., serotonin, norepinephrine, and dopamine) and exogenous amines such as tyramine, generating $\mathrm{H}_{2} \mathrm{O}_{2}$, aldehydes, and ammonia as by-products [36]. Since $\mathrm{MAO}$ is divided into MAO-A and MAO-B, amongst neurotransmitters oxidized by $\mathrm{MAO}$, serotonin oxidation is only catalysed by MAO-A, and norepinephrine, dopamine, epinephrine, and tyramine oxidization is catalysed by both MAO-A and MAO-B. Additionally, oxidation of phenylethylamine is catalysed by MAO-B [36, 43].

Several studies have reported on the role of these neurotransmitters in the pathophysiology of cardiovascular diseases (e.g., hypertension) [44-54].

4.2.1. Serotonin. High serotonin levels have been reported to play a role in the pathogenesis of cardiovascular diseases and hypertension [44-54]. A study conducted by Aflyatumova et al. looking at endothelin-1, nitric oxide, and serotonin in male adolescents showed that both endothelin-1 and serotonin serum concentration levels were increased in prehypertensive and hypertensive individuals compared to controls. They also observed increased levels of NO in prehypertensive individuals compared to controls and hypertensive individuals [54]. Serotonin has also been implicated to play a role in hypertensive disorders of pregnancy [55-57]. Recently, it has been reported that women 


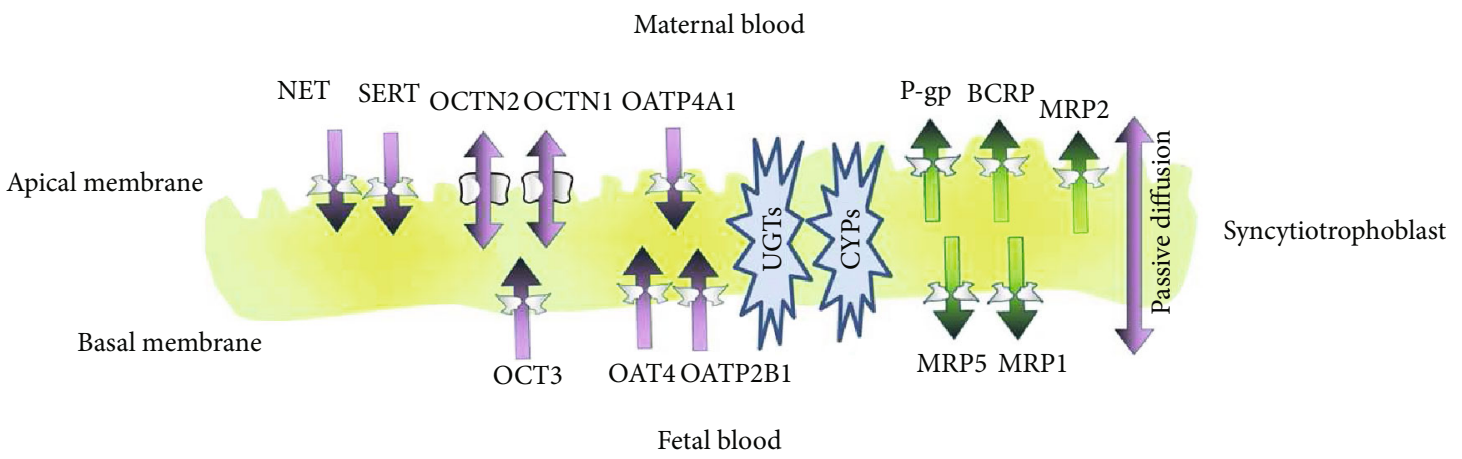

FIGURE 1: A schematic diagram showing norepinephrine transporter (NET) in the syncytiotrophoblast layer of the placenta. Norepinephrine from the maternal circulation enters the placenta and is transported to the fetal blood by NET [80].

TABLE 1: A comprehensive list of studies in this review examining the role of neurotransmitters oxidized by monoamine oxidases (MAO) in hypertensive disorders of pregnancy.

\begin{tabular}{lcr}
\hline Author & Neurotransmitters & Main findings \\
\hline$[60,61]$ & Serotonin & Increase in the urinary excretion of serotonin metabolites in preeclampsia \\
{$[59]$} & Elevated levels of serotonin in the placentas of preeclamptic patients compared to controls \\
{$[62]$} & Pregnant women exposed to serotonin had no increased risk of PE. \\
{$[73]$} & Adrenaline & NETs are expressed at minimal amounts in preeclamptic pregnancies. \\
{$[76]$} & Norepinephrine & NE concentration is increased in preeclamptic women compared to normal pregnant women. \\
{$[77]$} & Increase in plasma levels of norepinephrine in women with previous history of PE \\
{$[78]$} &
\end{tabular}

exposed to serotonin therapy had risk of preeclampsia and gestational hypertension [58]. Poulson et al. suggested that serotonin plays a role in the pathophysiology of preeclampsia [55-57]. These findings were verified by Senior et al., who observed elevated levels of serotonin in the placentas of preeclamptic patients compared to controls [59]. Other studies have reported that there is an increase in the urinary excretion of serotonin metabolites in preeclampsia $[60,61]$. In contrast, Lupattelli et al. showed that pregnant women exposed to serotonin had no increased risk of PE [62]. Pathophysiological mechanism underlying the association between serotonin and preeclampsia is unclear. However, we speculate that the underlying mechanism involves increased endothelin-1 (ET-1) and reduced nitric oxide (NO) levels.

Both ET-1 and NO have been reported to play a role in hypertensive disorders of pregnancy [63-68]. Endothelin-1 and $\mathrm{NO}$ are located in the endothelium and they play different roles. Endothelin-1 acts as a vasoconstrictor and NO inhibits the expression of adhesion molecules and platelet aggregation and acts as a vasodilator [69]. Interestingly, serotonin also acts as a vasoconstrictor which makes it possible that inducing AT-1 might lead to decreased NO and increased serotonin levels which leads to increased blood pressure.

Currently, there is very limited data associating serotonin levels and the risk of gestational hypertension. Therefore, more studies are needed to confirm whether serotonin exposure during pregnancy leads to adverse effects or not.

4.2.2. Adrenaline. Catecholamines such as noradrenaline and adrenaline have also been implicated in the pathophysiology of hypertension and hypertensive disorders in pregnancy [70-72]. A study conducted by øian et al. showed that arterial adrenaline was associated with mean arterial blood pressure in preeclamptic patients [73]. However, their findings were in contrast with those of a previous study by Pedersen et al., who observed no significant difference between adrenaline and noradrenaline levels of preeclamptic compared to normotensive women [74]. There is also very few data reporting on the association between catecholamines and hypertensive disorders of pregnancy. More studies are needed in order to see how they are regulated in the presence of PE or GH.

4.2.3. Norepinephrine. Norepinephrine is another type of catecholamine released during pregnancy. In normal pregnancy, the placenta expresses norepinephrine transporters (NETs) that are responsible for maintaining normal fetal circulation and fetomaternal exchange (Figure 1) [75]. It has been reported that the NETs are expressed at minimal amounts in preeclamptic pregnancies [76]. A study conducted by $\mathrm{Na}$ et al. reported a reduced NET mRNA expression in preeclamptic placentas compared with normal placentas. More interestingly, they also observed that maternal plasma NE concentration was increased in preeclamptic women compared to normal pregnant women [77]. Similar findings were observed by Lampinen et al., who also noted an increase in plasma levels of norepinephrine in women with a previous history of PE [78]. Since catecholamines also accumulate in platelets, association between increased platelet NE and the risk of preeclampsia was reported by O'Shaughnessy et al. [79]. Table 1 indicates a comprehensive 
TABLE 2: A comprehensive list of studies in this review examining the role of catechol-O-methyl transferase (COMT) in the pathophysiology of hypertensive disorders of pregnancy.

\begin{tabular}{|c|c|c|c|c|}
\hline Author & Country & Design & Cohort size & Main findings \\
\hline [32] & $\begin{array}{l}\text { United } \\
\text { States }\end{array}$ & Cohort & $\begin{array}{l}270 \text { normal women } \\
284 \text { women with hypertension }\end{array}$ & COMT activity is low in patients with hypertension. \\
\hline [86] & $\begin{array}{l}\text { United } \\
\text { States }\end{array}$ & Review & Preeclamptic women & $\begin{array}{l}\text { Deficiency in catechol-O-methyl transferase and } \\
\text { 2-methoxyoestradiol is associated with preeclampsia. }\end{array}$ \\
\hline [87] & Australia & Cohort & $\begin{array}{l}14 \text { healthy term pregnant women } \\
8 \text { preterm normotensive pregnancy } \\
22 \text { severe preeclamptic women }\end{array}$ & $\begin{array}{l}\text { Severe preeclampsia may not be associated with a } \\
\text { decrease in placental COMT expression. }\end{array}$ \\
\hline [18] & China & Cohort & $\begin{array}{l}15 \text { normal pregnant women } \\
15 \text { term pregnant patients with } \\
\text { preeclampsia }\end{array}$ & $\begin{array}{l}\text { COMT may play a role in the pathogenesis of term } \\
\text { preeclampsia. }\end{array}$ \\
\hline$[90]$ & Spain & Cohort & Pregnant Sprague-Dawley rats & $\begin{array}{l}\text { COMT is associated with reduced NO bioavailability } \\
\text { which results to endothelial dysfunction in GH. }\end{array}$ \\
\hline
\end{tabular}

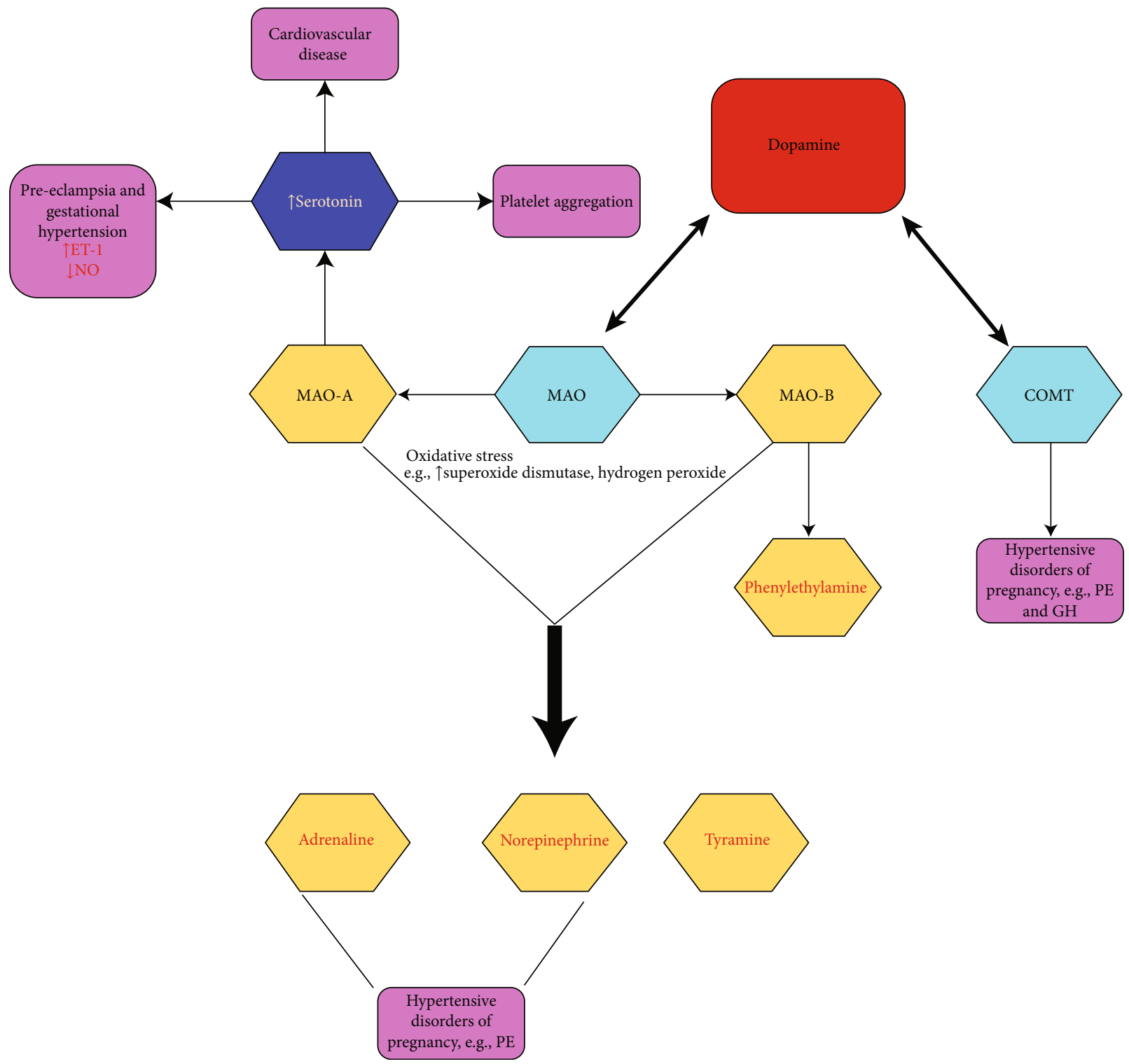

FIGURE 2: Schematic showing the role of dopamine-induced oxidative stress in the pathophysiology of hypertensive disorders of pregnancy such as PE and GH. 
list of studies in this review examining the role of neurotransmitters oxidized by monoamine oxidases (MAO) in hypertensive disorders of pregnancy.

\section{The Role of Catechol-O-methyl Transferase (COMT) in the Pathophysiology of Hypertensive Disorders of Pregnancy}

Catechol-O-methyl transferase (COMT) is a key enzyme involved in catecholamine and estrogen degradation [81], and it was found to be active in both the placenta and the decidua [82]. Catechol-O-methyl transferase (COMT) has been reported to be involved in trophoblast invasion [83]. Reduced COMT bioavailability has been reported to be associated with hypertensive disorders of pregnancy $[84,85]$. A study conducted by Kanasaki et al. reported that pregnant mice deficient in COMT developed multiple functional and structural features of preeclampsia-like phenotype due to the absence of 2-ME which is a metabolite of $17 \beta$-estradiol generated by COMT [86]. Similarly, Lai et al. observed decreased expression of COMT in the placentas from term preeclamptic patient [18]. In contrast, a study conducted by Palmer et al. reported that there was no significant difference in placental COMT expression in preeclamptic women compared to normotensive women. Their findings suggested that preeclampsia may not be associated with a decrease in placental COMT expression [87]. More studies are needed to confirm how COMT is regulated in the presence of $\mathrm{PE}$ in order to have a better understanding on the pathophysiology of the disease.

A number of studies highlighted the role of COMT in gestational hypertension $[88,89]$. A recent study done by Hernandez et al. reported that the inhibition of COMT was associated with reduced NO bioavailability which resulted in endothelial dysfunction in GH [90]. However, more studies are needed to investigate the COMT mechanisms involved in the pathophysiology of both PE and GH. Table 2 shows a summary of studies that have been done to date examining the role of catechol-O-methyl transferase (COMT) in the pathophysiology of hypertensive disorders of pregnancy, and Figure 2 summarizes the role of dopamine in the pathophysiology of hypertensive disorders of pregnancy such as PE and GH.

\section{Conclusion}

MAO and COMT are dysregulated in the presence of both $\mathrm{PE}$ and $\mathrm{GH}$. More research is needed to investigate how these enzymes are regulated in the presence of each disorder in order to help develop effective antihypertensive drugs that can inhibit or stabilize the levels of these enzymes in pregnancy. This will help in improving prenatal diagnostic procedures and reducing maternal and fetal death rates.

\section{Conflicts of Interest}

The author declares no conflicts of interest.

\section{References}

[1] (NIH) NIoH, National Heart, Lung, and Blood Institute. National High Blood Pressure Education Program: working group report on high blood pressure in pregnancy, NIH Publication, 2000.

[2] Pregnancy TFoHi, Hypertension, Pregnancy-Induced-Practice Guideline, American College of Obstetricians and Gynecologists, 2013.

[3] L. O. Kurlak, A. Green, P. Loughna, and F. Broughton Pipkin, "Oxidative stress markers in hypertensive states of pregnancy: preterm and term disease," Frontiers in Physiology, vol. 5, p. 310, 2014.

[4] G. J. Burton and E. Jauniaux, "Oxidative stress," Best Practice \& Research Clinical Obstetrics \& Gynaecology, vol. 25, no. 3, pp. 287-299, 2011.

[5] C. A. Hubel, J. M. Roberts, R. N. Taylor, T. J. Musci, G. M. Rogers, and M. K. McLaughlin, "Lipid peroxidation in pregnancy: new perspectives on preeclampsia," American Journal of Obstetrics \& Gynecology, vol. 161, no. 4, pp. 1025-1034, 1989.

[6] M. R. Sutherland, M. Bertagnolli, M.-A. Lukaszewski et al., "Preterm birth and hypertension risk: the oxidative stress paradigm," Hypertension, vol. 63, no. 1, pp. 12-18, 2014.

[7] I. Armando, V. A. M. Villar, and P. A. Jose, "Dopamine and renal function and blood pressure regulation," Comprehensive Physiology, vol. 1, no. 3, pp. 1075-1117, 2011.

[8] T. G. Hastings, "Enzymatic oxidation of dopamine: the role of prostaglandin H synthase," Journal of Neurochemistry, vol. 64, no. 2, pp. 919-924, 1995.

[9] S. B. Berman and T. G. Hastings, "Dopamine oxidation alters mitochondrial respiration and induces permeability transition in brain mitochondria: implications for Parkinson's disease," Journal of Neurochemistry, vol. 73, no. 3, pp. 1127-1137, 1999.

[10] P. M. Sinet, R. E. Heikkila, and G. Cohen, "Hydrogen peroxide production by rat brain in vivo," Journal of Neurochemistry, vol. 34, no. 6, pp. 1421-1428, 1980.

[11] H. S. Maker, C. Weiss, D. J. Silides, and G. Cohen, "Coupling of dopamine oxidation (monoamine oxidase activity) to glutathione oxidation via the generation of hydrogen peroxide in rat brain homogenates," Journal of Neurochemistry, vol. 36, no. 2, pp. 589-593, 1981.

[12] G. Grima, B. Benz, V. Parpura, M. Cuénod, and K. Q. Do, "Dopamine-induced oxidative stress in neurons with glutathione deficit: implication for schizophrenia," Schizophrenia Research, vol. 62, no. 3, pp. 213-224, 2003.

[13] Y. Luo and G. S. Roth, "The roles of dopamine oxidative stress and dopamine receptor signaling in aging and age-related neurodegeneration," Antioxidants and Redox Signaling, vol. 2, no. 3, pp. 449-460, 2000.

[14] J. D. Guo, X. Zhao, Y. Li, G. R. Li, and X. L. Liu, "Damage to dopaminergic neurons by oxidative stress in Parkinson's disease (review)," International Journal of Molecular Medicine, vol. 41, no. 4, pp. 1817-1825, 2018.

[15] E. Monzani, S. Nicolis, S. Dell'Acqua et al., "Dopamine, oxidative stress and protein-quinone modifications in Parkinson's and other neurodegenerative diseases," Angewandte Chemie International Edition, vol. 58, no. 20, pp. 6512-6527, 2019.

[16] N. Abdelouahab, G. Huel, A. Suvorov et al., "Monoamine oxidase activity in placenta in relation to manganese, 
cadmium, lead, and mercury at delivery," Neurotoxicology and Teratology, vol. 32, no. 2, pp. 256-261, 2010.

[17] G. R. Auda, S. H. Kirk, M. A. Billett, and E. E. Billett, "Localization of monoamine oxidase mRNA in human placenta," Journal of Histochemistry \& Cytochemistry, vol. 46, no. 12, pp. 1393-1400, 1998.

[18] B. Lai, C. Wang, L. Zhou, J. Wang, and H. Wu, "Reduced expression of COMT in placenta correlates with term preeclampsia," Advances in Bioscience and Biotechnology, vol. 4, no. 4, pp. 44-49, 2013.

[19] B. Wahlund, J. Sääf, and L. Wetterberg, "Clinical symptoms and platelet monoamine oxidase in subgroups and different states of affective disorders," Journal of Affective Disorders, vol. 35, no. 1-2, pp. 75-87, 1995.

[20] M. Berry, A. Juorio, and I. Paterson, "The functional role of monoamine oxidases A and B in the mammalian central nervous system," Progress in Neurobiology, vol. 42, no. 3, pp. 375-391, 1994.

[21] T. Egashira, "Studies on monoamine oxidase. XVIII. Enzymic properties of placental monoamine oxidase," The Japanese Journal of Pharmacology, vol. 26, no. 4, pp. 493-500, 1976.

[22] L. A. Riley, M. Waguespack, and R. M. Denney, "Characterization and quantitation of monoamine oxidases $\mathrm{A}$ and $\mathrm{B}$ in mitochondria from human placenta," Molecular Pharmacology, vol. 36, no. 1, pp. 54-60, 1989.

[23] S. Marcus, K. Barry, H. Flynn, R. Tandon, and J. Greden, "Treatment guidelines for depression in pregnancy," International Journal of Gynecology \& Obstetrics, vol. 72, no. 1, pp. 61-70, 2001.

[24] Z. Koren, Y. Pfeifer, and F. Sulman, "Deleterious effect of the monoamine oxidase inhibitor pargyline on pregnant rats," Fertility and Sterility, vol. 16, no. 3, pp. 393-400, 1965.

[25] S. T. Chao and M. R. Juchau, "Placental drug Metabolism," in Teratogenesis and Reproductive Toxicology, pp. 31-48, Springer, 1983.

[26] E. Barnea, N. MacLusky, A. DeCherney, and F. Naftolin, "Monoamine oxidase activity in the term human placenta," American Journal of Perinatology, vol. 3, no. 3, pp. 219-224, 1986.

[27] A. Sturza, M. S. Leisegang, A. Babelova et al., "Monoamine oxidases are mediators of endothelial dysfunction in the mouse aorta," Hypertension, vol. 62, no. 1, pp. 140-146, 2013.

[28] X.-Q. Sun, E. Peters, I. Schalij et al., "The effect of monoamine oxidase A inhibition on experimentally induced pulmonary arterial hypertension," European Respiratory Journal, vol. 52, 2018.

[29] L. C. Sánchez-Aranguren, C. E. Prada, C. E. Riaño-Medina, and M. Lopez, "Endothelial dysfunction and preeclampsia: role of oxidative stress," Frontiers in Physiology, vol. 5, p. 372, 2014.

[30] E. Poniedziałek-Czajkowska, R. Mierzyński, D. Dłuski, and B. Leszczyńska-Gorzelak, "Adipokines and endothelium dysfunction markers in pregnant women with gestational hypertension," International Journal of Hypertension, vol. 2019, Article ID 7541846, 10 pages, 2019.

[31] O. Duicu, A. Sturza, L. Noveanu, and D. Muntean, "Mitochondria and endothelial dysfunction: a glimpse of monoamine oxidases," Experimental \& Clinical Cardiology, Supplement A, pp. 52A-56A, 2013.

[32] A. Sturza, L. Noveanu, O. Duicu, and D. Muntean, "P172 Monoamine oxidase inhibition corrects endothelial dysfunc- tion in experimental diabetes," Cardiovascular Research, vol. 103, Supplement 1, pp. S30.3-S3S30, 2014.

[33] M. A. Kluge, J. L. Fetterman, and J. A. Vita, "Mitochondria and endothelial function," Circulation Research, vol. 112, no. 8, pp. 1171-1188, 2013.

[34] A. Sturza, L. Noveanu, O. Duicu, D. Angoulvant, and D. M. Muntean, "0209: monoamine oxidases as novel sources of reactive oxygen species in experimental diabetes," Archives of Cardiovascular Diseases Supplements, vol. 6, p. 15, 2014.

[35] R. Lighezan, A. Sturza, O. M. Duicu et al., "Monoamine oxidase inhibition improves vascular function in mammary arteries from nondiabetic and diabetic patients with coronary heart disease," Canadian Journal of Physiology and Pharmacology, vol. 94, no. 10, pp. 1040-1047, 2016.

[36] M. B. Youdim, D. Edmondson, and K. F. Tipton, "The therapeutic potential of monoamine oxidase inhibitors," Nature reviews Neuroscience, vol. 7, no. 4, pp. 295-309, 2006.

[37] M. A. De Vera and A. Bérard, "Antidepressant use during pregnancy and the risk of pregnancy-induced hypertension," British Journal of Clinical Pharmacology, vol. 74, no. 2, pp. 362-369, 2012.

[38] R. Aouache, L. Biquard, D. Vaiman, and F. Miralles, "Oxidative stress in preeclampsia and placental diseases," International Journal of Molecular Sciences, vol. 19, no. 5, p. 1496, 2018.

[39] S. R. Hansson, Å. Nääv, and L. Erlandsson, “Oxidative stress in preeclampsia and the role of free fetal hemoglobin," Frontiers in Physiology, vol. 5, p. 516, 2015.

[40] D. I. Chiarello, C. Abad, D. Rojas et al., "Oxidative stress: normal pregnancy versus preeclampsia," Biochimica et Biophysica Acta (BBA) - Molecular Basis of Disease, no. article 165354, 2018.

[41] D. Draganovic, N. Lucic, and D. Jojic, "Oxidative stress marker and pregnancy induced hypertension," Medical Archives, vol. 70, no. 6, pp. 437-440, 2016.

[42] S. Mohanty, P. Sahu, M. Mandal, P. Mohapatra, and A. Panda, "Evaluation of oxidative stress in pregnancy induced hypertension," Indian Journal of Clinical Biochemistry, vol. 21, no. 1, pp. 101-105, 2006.

[43] D. Maggiorani, N. Manzella, D. E. Edmondson et al., "Monoamine oxidases, oxidative stress, and altered mitochondrial dynamics in cardiac ageing," Oxidative Medicine and Cellular Longevity, vol. 2017, Article ID 3017947, 8 pages, 2017.

[44] R. R. Nigmatullina, V. V. Kirillova, R. K. Jourjikiya et al., "Disrupted serotonergic and sympathoadrenal systems in patients with chronic heart failure may serve as new therapeutic targets and novel biomarkers to assess severity, progression and response to treatment," Cardiology, vol. 113, no. 4, pp. 277-286, 2009.

[45] A. M. Selim, N. Sarswat, I. Kelesidis, M. Iqbal, R. Chandra, and R. Zolty, "Plasma serotonin in heart failure: possible marker and potential treatment target," Heart, Lung and Circulation, vol. 26, no. 5, pp. 442-449, 2017.

[46] C. Rouzaud-Laborde, C. Delmas, N. Pizzinat et al., "Platelet activation and arterial peripheral serotonin turnover in cardiac remodeling associated to aortic stenosis," American Journal of Hematology, vol. 90, no. 1, pp. 15-19, 2015.

[47] F. Côté, C. Fligny, E. Bayard et al., "Maternal serotonin is crucial for murine embryonic development," Proceedings of the National Academy of Sciences of the United States of America, vol. 104, no. 1, pp. 329-334, 2007. 
[48] E. Van den Berg, J. Schmitz, C. Benedict, C. Malloy, J. Willerson, and G. Dehmer, "Transcardiac serotonin concentration is increased in selected patients with limiting angina and complex coronary lesion morphology," Circulation, vol. 79, no. 1, pp. 116-124, 1989.

[49] M. H. Pietraszek, Y. Takada, A. Takada et al., "Blood serotonergic mechanisms in type 2 (non-insulin-dependent) diabetes mellitus," Thrombosis Research, vol. 66, no. 6, pp. 765774, 1992.

[50] B. Brenner, J. Harney, B. Ahmed et al., "Plasma serotonin levels and the platelet serotonin transporter," Journal of Neurochemistry, vol. 102, no. 1, pp. 206-215, 2007.

[51] K. Vikenes, M. Farstad, and J. E. Nordrehaug, "Serotonin is associated with coronary artery disease and cardiac events," Circulation, vol. 100, no. 5, pp. 483-489, 1999.

[52] M. Biondi, A. Agostoni, and B. Marasini, "Serotonin levels in hypertension," Journal of hypertension Supplement, vol. 4, no. 1, pp. S39-S41, 1986.

[53] R. P. Davis, T. Szasz, H. Garver, R. Burnett, N. R. Tykocki, and S. W. Watts, "One-month serotonin infusion results in a prolonged fall in blood pressure in the deoxycorticosterone acetate (DOCA) salt hypertensive rat," ACS Chemical Neuroscience, vol. 4, no. 1, pp. 141-148, 2012.

[54] G. N. Aflyatumova, R. R. Nigmatullina, D. I. Sadykova, M. D. Chibireva, F. Fugetto, and R. Serra, "Endothelin-1, nitric oxide, serotonin and high blood pressure in male adolescents," Vascular Health and Risk Management, vol. 14, pp. 213-223, 2018.

[55] E. Poulson, M. Botros, and J. M. Robson, "Effect of 5hydroxytryptamine and iproniazid on pregnancy," Science, vol. 131, no. 3407, pp. 1101-1102, 1960.

[56] A. C. Bolte, H. P. van Geijn, and G. A. Dekker, "Pathophysiology of preeclampsia and the role of serotonin," European Journal of Obstetrics \& Gynecology and Reproductive Biology, vol. 95, no. 1, pp. 12-21, 2001.

[57] C. P. Weiner, "The role of serotonin in the preeclampsiaeclampsia syndrome," Cardiovascular Drugs and Therapy, vol. 4, no. 1, pp. 37-43, 1990.

[58] S. Toh, A. A. Mitchell, C. Louik, M. M. Werler, C. D. Chambers, and S. Hernandez-Diaz, "Selective serotonin reuptake inhibitor use and risk of gestational hypertension," The American Journal of Psychiatry, vol. 166, no. 3, pp. 320-328, 2009.

[59] J. B. Senior, I. Fahim, F. M. Sullivan, and J. M. Robson, "Possible role of 5-hydroxytryptamine in toxaemia of pregnancy," The Lancet, vol. 282, no. 7307, pp. 553-554, 1963.

[60] G. M. Filshie, P. Maynard, C. Hutter, J. C. Cooper, G. Robinson, and P. Rubin, "Urinary 5-hydroxyindole acetate concentration in pregnancy induced hypertension," British Medical Journal, vol. 304, no. 6836, p. 1223, 1992.

[61] Y. Ishii, H. Kanai, A. Maezawa, A. Tsuchida, S. Yano, and T. Naruse, "Evaluation of intraplatelet and urinary 5hydroxytryptamine (5-HT), and urinary 5hydroxyindoleacetic acid (5-HIAA) levels in patients with toxemia of pregnancy," Research Communications in Chemical Pathology and Pharmacology, vol. 80, no. 1, pp. 21-40, 1993.

[62] A. Lupattelli, M. Wood, K. Lapane, O. Spigset, and H. Nordeng, "Risk of preeclampsia after gestational exposure to selective serotonin reuptake inhibitors and other antidepressants: a study from The Norwegian Mother and Child Cohort Study," Pharmacoepidemiology and Drug Safety, vol. 26, no. 10, pp. 1266-1276, 2017.
[63] L. Saleh, K. Verdonk, W. Visser, A. H. van den Meiracker, and A. H. Danser, "The emerging role of endothelin-1 in the pathogenesis of pre-eclampsia," Therapeutic Advances in Cardiovascular Disease, vol. 10, no. 5, pp. 282-293, 2016.

[64] A. Jain, "Endothelin-1: a key pathological factor in preeclampsia?," Reproductive Biomedicine Online, vol. 25, no. 5, pp. 443-449, 2012.

[65] Y.-P. Lu, A. A. Hasan, S. Zeng, and B. Hocher, "Plasma ET-1 concentrations are elevated in pregnant women with hypertension-meta-analysis of clinical studies," Kidney and Blood Pressure Research, vol. 42, no. 4, pp. 654-663, 2017.

[66] E. O. Darkwa, R. Djagbletey, R. Essuman, D. Sottie, G. B. Dankwah, and G. Aryee, "Nitric oxide and pre-eclampsia: a comparative study in Ghana," Open Access Macedonian Journal of Medical Sciences, vol. 6, no. 6, pp. 1023-1027, 2018.

[67] K. Adu-Bonsaffoh, D. A. Antwi, S. A. Obed, and B. Gyan, "Nitric oxide dysregulation in the pathogenesis of preeclampsia among Ghanaian women," Integrated Blood Pressure Control, vol. 8, pp. 1-6, 2015.

[68] S. Meher and L. Duley, "Nitric oxide for preventing preeclampsia and its complications," Cochrane Database of Systematic Reviews, vol. 2, 2007.

[69] M. Akcaboy, S. Kula, T. Göktas et al., "Effect of plasma NOx values on cardiac function in obese hypertensive and normotensive pediatric patients," Pediatric Nephrology, vol. 31, no. 3, pp. 473-483, 2016.

[70] P. G. Natrajan, H. H. G. MCGARRTGLE, D. M. Lawrence, and G. C. L. Lachelin, "Plasma noradrenaline and adrenaline levels in normal pregnancy and in pregnancy-induced hypertension," BJOG: An International Journal of Obstetrics \& Gynaecology, vol. 89, no. 12, pp. 1041-1045, 1982.

[71] P. Blankestijn, J. Tulen, F. Boomsma et al., "Support for adrenaline-hypertension hypothesis: 18 hour pressor effect after 6 hours adrenaline infusion," The Lancet, vol. 332, no. 8625, pp. 1386-1389, 1988.

[72] A. Luk, R. C. W. Ma, C. W. Lam et al., "A 21-year-old pregnant woman with hypertension and proteinuria," PLoS Medicine, vol. 6, no. 2, article e1000037, 2009.

[73] P. Oian, S. E. Kjeldsen, I. Eide, and J. M. Maltau, "Increased arterial catecholamines in pre-eclampsia," Acta Obstetricia et Gynecologica Scandinavica, vol. 65, no. 6, pp. 613-617, 1986.

[74] E. B. Pedersen, A. B. Rasmussen, N. J. Christensen et al., "Plasma noradrenaline and adrenaline in pre-eclampsia, essential hypertension in pregnancy and normotensive pregnant control subjects," Acta Endocrinologica, vol. 99, no. 4, pp. 594-600, 1982.

[75] L. Bzoskie, L. Blount, K. Kashiwai, Y. T. Tseng, W. W. Hay Jr., and J. F. Padbury, "Placental norepinephrine clearance: in vivo measurement and physiological role," American Journal of Physiology-Endocrinology and Metabolism, vol. 269, no. 1, pp. E145-E149, 1995.

[76] B. Bottalico, I. Larsson, J. Brodszki et al., "Norepinephrine transporter (NET), serotonin transporter (SERT), vesicular monoamine transporter (VMAT2) and organic cation transporters (OCT1, 2 and EMT) in human placenta from preeclamptic and normotensive pregnancies," Placenta, vol. 25, no. 6, pp. 518-529, 2004.

[77] K.-H. Na, J. H. Choi, C.-H. Kim, K.-S. Kim, and G. J. Kim, "Altered expression of norepinephrine transporter and norepinephrine in human placenta cause pre-eclampsia through 
regulated trophoblast invasion," Clinical and Experimental Reproductive Medicine, vol. 40, no. 1, pp. 12-22, 2013.

[78] K. H. Lampinen, M. Rönnback, P.-H. Groop, M. G. Nicholls, T. G. Yandle, and R. J. Kaaja, "Increased plasma norepinephrine levels in previously pre-eclamptic women," Journal of Human Hypertension, vol. 28, no. 4, pp. 269-273, 2014.

[79] R. O'Shaughnessy, R. Reiss, G. Scott-Tibbs, and E. McSweeney, "Plasma and platelet norepinephrine in normal and preeclamptic pregnancy," The Journal of Reproductive Medicine, vol. 32, no. 7, pp. 504-508, 1987.

[80] M. Rubinchik-Stern and S. Eyal, "Drug interactions at the human placenta: what is the evidence?," Frontiers in Pharmacology, vol. 3, p. 126, 2012.

[81] E. Yagi, J. C. Barrett, and T. Tsutsui, “The ability of four catechol estrogens of 17beta-estradiol and estrone to induce DNA adducts in Syrian hamster embryo fibroblasts," Carcinogenesis, vol. 22, no. 9, pp. 1505-1510, 2001.

[82] P. T. Männistö and S. Kaakkola, "Catechol-O-methyltransferase (COMT): biochemistry, molecular biology, pharmacology, and clinical efficacy of the new selective COMT inhibitors," Pharmacological Reviews, vol. 51, no. 4, pp. 593-628, 1999.

[83] A. Zhao, Y. Cheng, X. Li et al., "Promoter hypomethylation of COMT in human placenta is not associated with the development of pre-eclampsia," Molecular Human Reproduction, vol. 17, no. 3, pp. 199-206, 2010.

[84] K. Kanasaki and R. Kalluri, "The biology of preeclampsia," Kidney International, vol. 76, no. 8, pp. 831-837, 2009.

[85] E. Barnea, N. MacLusky, A. DeCherney, and F. Naftolin, "Catechol-o-methyl transferase activity in the human term placenta," American Journal of Perinatology, vol. 5, no. 2, pp. 121-127, 1988.

[86] K. Kanasaki, K. Palmsten, H. Sugimoto et al., "Deficiency in catechol-O-methyltransferase and 2-methoxyoestradiol is associated with pre-eclampsia," Nature, vol. 453, no. 7198, pp. 1117-1121, 2008.

[87] K. Palmer, B. Saglam, C. Whitehead, O. Stock, M. Lappas, and $\mathrm{S}$. Tong, "Severe early-onset preeclampsia is not associated with a change in placental catechol $\mathrm{O}$-methyltransferase (COMT) expression," The American Journal of Pathology, vol. 178 , no. 6 , pp. 2484-2488, 2011.

[88] L. T. Roten, M. H. Fenstad, S. Forsmo et al., "A low COMT activity haplotype is associated with recurrent preeclampsia in a Norwegian population cohort (HUNT2)," Molecular Human Reproduction, vol. 17, no. 7, pp. 439-446, 2011.

[89] L. D. Hill, T. P. York, J. P. Kusanovic et al., "Epistasis between COMT and MTHFR in maternal-fetal dyads increases risk for preeclampsia," PLoS One, vol. 6, no. 1, article e16681, 2011.

[90] M. Hernandez, I. Hernandez, F. Rodriguez et al., "Endothelial dysfunction in gestational hypertension induced by catecholO-methyltransferase inhibition," Experimental Physiology, vol. 98, no. 3, pp. 856-866, 2013. 


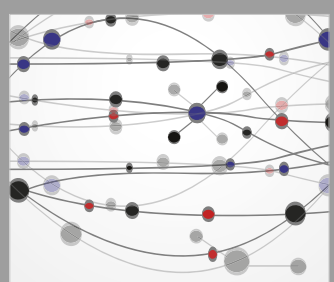

The Scientific World Journal
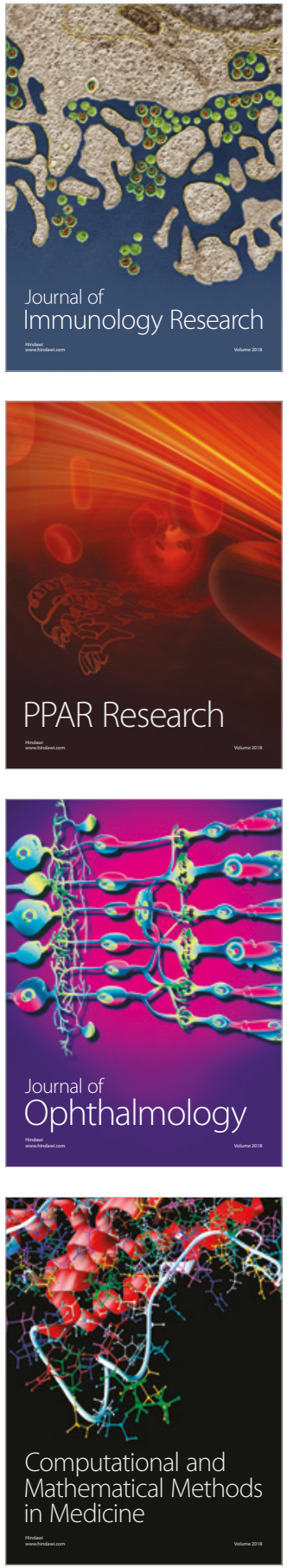

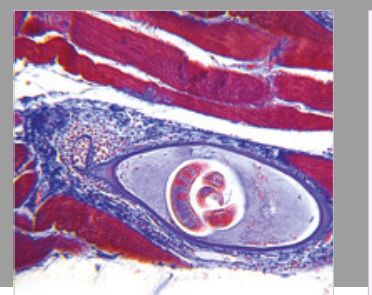

Gastroenterology Research and Practice

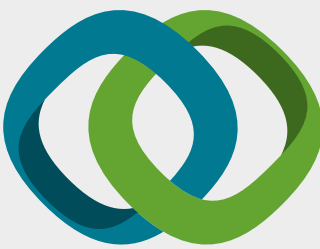

\section{Hindawi}

Submit your manuscripts at

www.hindawi.com
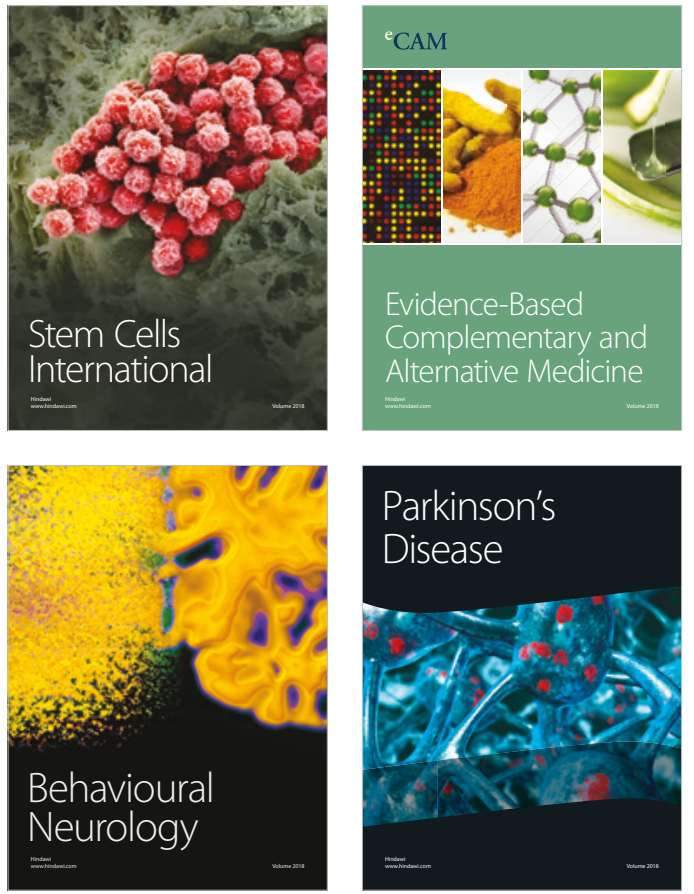

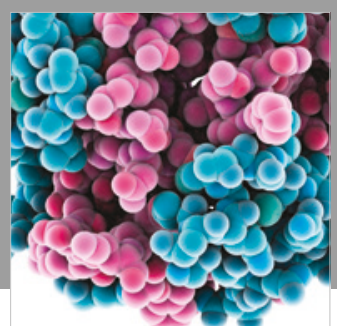

ournal of

Diabetes Research

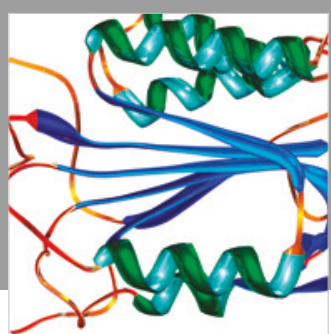

Disease Markers
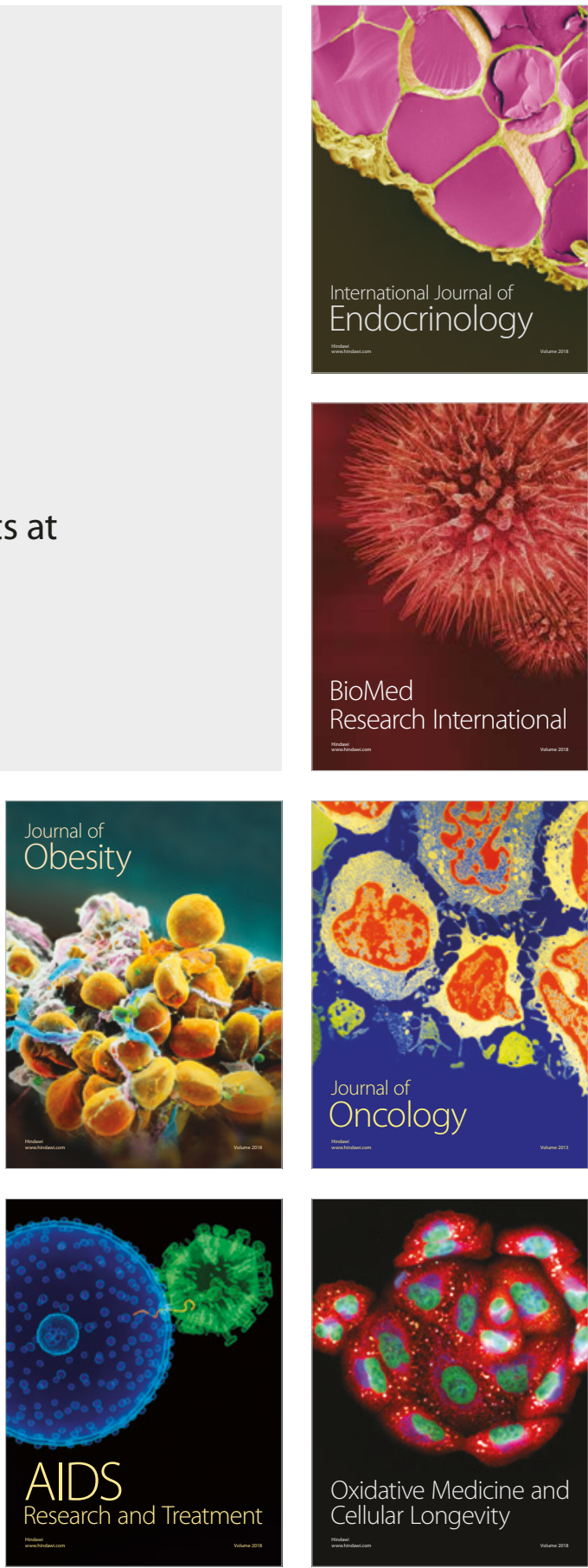